\title{
Trente Ans, ou la Vie d'un Joueur, de Victor Ducange, en Buenos Aires. La suerte de un jugador y la gloria de un dramaturgo
}

\author{
Luis Marcelo MARTINO \\ Universidad Nacional de Tucumán (Argentina) \\ marcelo_martino@hotmail.com
}

Recibido: $17 / 08 / 2016$

Aceptado: 27/09/2016

\section{Resumen}

Desde 1831, año en que se estrena Trente Ans, ou la Vie d'un Joueur, suben a los escenarios de Buenos Aires numerosos dramas de Victor Ducange. La Gaceta Mercantil y el Diario de la Tarde, dos de los principales periódicos de la época, se hacen eco en sus páginas de las novedades teatrales, ya sea a través de breves anuncios, editoriales o cartas de lectores. El presente trabajo se propone, a través del análisis de dichos textos, identificar y caracterizar el fenómeno de la recepción de Trente Ans en Buenos Aires, así como también reconstruir el proceso de consagración local de Ducange como dramaturgo, vinculado estrechamente con aquella pieza.

Palabras clave: Romanticismo, Victor Ducange, drama, literatura francesa en Argentina.

\section{Trente Ans, ou la Vie d'un Joueur, de Victor Ducange, à Buenos Aires.}

\section{Le sort d'un joueur et la gloire d'un dramaturge}

\section{Résumé1}

À partir de 1831, l'année où Trente Ans, ou La Vie d'un Joueur est joué pour la première fois, de nombreux drames de Victor Ducange sont mis en scène à Buenos Aires. Les journaux La Gaceta Mercantil et le Diario de la Tarde, qui sont deux des journaux principaux de l'époque, informaient le public des nouveautés en théâtre, soit par de petites annonces, soit par des éditoriaux ou par le courrier des lecteurs. Ce travail se propose d'identifier et de caractériser l'accueil à Trente Ans à Buenos Aires, à travers l'analyse de ces textes, ainsi que de reconstruire le processus de consécration locale de Ducange comme dramaturge, lequel est fortement lié à cette pièce.

Mots clés: Romantisme, Victor Ducange, drame, littérature française á Buenos Aires.

${ }^{1}$ La traducción al francés fue realizada por Julia Ilte. 


\title{
Trente Ans, ou la Vie d'un Joueur, of Victor Ducange, in Buenos Aires. The Gambler's Fortune and the Playwright's Glory
}

\begin{abstract}
After 1831, when Trente Ans, ou la Vie d'un Joueur premiered, several dramas by Victor Ducange were performed in Buenos Aires. Theater news were circulated by two of the leading newspapers at that timeLa Gaceta Mercantil and Diario de la Tarde-through announcements, editorials and letters from readers. The purpose of this essay is to analyze these journalistic texts with the aim of characterizing the reception of Trente Ans in Buenos Aires, and of reconstructing the process of Ducange's local consecration as a playwright, whose recognition was closely attached to that play.
\end{abstract}

Keywords: Romanticism, Victor Ducange, drama, French literature in Argentina.

Sumario: Un torrente de libros. Ducange en las tablas de Buenos Aires. Un jugador afortunado. Célebre, inmortal e ingenioso. Consideraciones finales.

\section{Referencia normalizada}

Martino, L. M. (2016). «Trente Ans, ou la Vie d'un Joueur, de Victor Ducange, en Buenos Aires. La suerte de un jugador y la gloria de un dramaturgo ». Thélème. Revista Complutense de Estudios Franceses, Vol. 31, Núm. 2 :297-313. http://dx.doi.org/10.5209/rev_THEL.2016.v31.n2.53326

\section{Un torrente de libros}

Juan Bautista Alberdi, uno de los principales referentes de la llamada "generación romántica" argentina o "generación del 37", relata en uno de sus textos autobiográficos su primer encuentro con la literatura de Jean-Jacques Rousseau. En 1829, durante su juventud, en una de las aulas del Colegio de Ciencias Morales, Alberdi inicia la lectura (furtiva) de La Nouvelle Héloïse. Pero el ejemplar no le pertenece. Accede a él a instancias de su compañero de banco, Miguel Cané, quien se lo presta en el transcurso de una clase de latín (Alberdi, 2010: 172). Se trataría, en apariencia, de una versión española -Cané se refiere al libro como "Una novela de amor, que se titula Julia o la Nueva Eloísa" (Alberdi, 2010: 172)-, probablemente de la traducción de José Marchena, publicada por primera vez en 1821 (Baquero Escudero, 2002: 395) y que, según consta en el Catálogo de la Librería de los Sres. Duportail Hermanos (1829) (Parada, 2002: 53), ya estaba disponible en Buenos Aires.

Esta anécdota ${ }^{2}$ constituye un valioso testimonio de la circulación de la literatura francesa en el Buenos Aires de la década del 30 -y fines de la del 20- del siglo XIX, y del interés que concita entre el sector ilustrado de la población. El citado catálogo

\footnotetext{
${ }^{2}$ Para un análisis de esta particular "escena de lectura", cfr. el trabajo de Luis M. Martino (2016).
} 
de la librería de los Duportail registra, de hecho, la presencia de 144 autores de nacionalidad francesa y de 173 libros escritos en esa lengua (Parada, 2002: 18; 23).

Parada destaca, además, "la significativa presencia de la literatura de ficción" francesa, fundamentalmente novelas, género que representaría un $25 \%$ de las obras registradas en el catálogo (Parada, 2010: 25). A través del análisis de anuncios de ventas de libros publicados por tres periódicos de Buenos Aires -El Monitor, El Lucero y Diario de la Tarde- entre 1829 y 1835, Ana Eugenia Vázquez constata, por su parte que "el mayor número de relevos corresponde a textos ficcionales, en su gran mayoría, novelas francesas", principalmente de François-René de Chateaubriand, Rousseau y Madame de Staël (Vázquez, 2015: 441).

Un gran porcentaje de las obras que se ofrecían en los anuncios de la prensa periódica y en los estantes de las librerías de la época, habría ingresado a estas tierras a impulsos de la revolución de julio de 1830 en Francia. Vicente Fidel López, otro de los representantes del romanticismo argentino, da cuenta del impacto de dicho evento en el escenario cultural de Buenos Aires, que

produjo una entrada torrencial de libros y autores que no se había oído mencionar hasta entonces. Las obras de Cousin, de Villemain, de Quinet, Michelet, Jules Janin, Merimée, Nisard, etc., andaban en nuestras manos produciendo una novelería fantástica de ideas y de prédicas sobre escuelas y autores románticos, clásicos, eclécticos, San Simonianos. Nos arrebatábamos las obras de Víctor Hugo, de Sainte Beuve, las tragedias de Casimir Delavigne, los dramas de Dumas y de Víctor Ducange, George Sand, etc. [...]. La Revue de París, donde todo lo nuevo y trascendental de la literatura francesa de 1830 ensayó sus fuerzas, era buscada como lo más palpitante de nuestros deseos (López, s/a: 16-17).

El interés por las publicaciones recientes y las novedades literarias, así como el consiguiente desplazamiento de productos más bien tradicionales se refleja de manera elocuente en una obra dramática local: Don Tadeo, de Claudio Cuenca. Esta comedia -escrita en el período en el que Juan Manuel de Rosas gobernó Buenos Aires (18291851) pero publicada póstumamente en 1860 (Binayán, 1926: 366) y cuya acción transcurre en Buenos Aires entre 1832 y 1838 (Parada, 2010: 28)- cuenta entre sus personajes a un librero especializado en publicaciones religiosas, don Diego, quien se queja del cambio de gusto del público lector:

D. DIEGO: Cansado estoy de ofrecer

En los diarios las novenas

De San Ignacio, San-Juan,

San Serapio, San-Damián,

Y otras mil, a cual más buenas.

[...]

D. TADEO: ¿Y no compran?

D. DIEGO: Ay!.. me abrumas...

Sué, Ducange, Beranger,

Scott, Scribe, L'Herminier [sic],

Víctor Hugo, Blaire, Dumas,

Chateaubriand y otros así 
No más piden; [... $]^{3}$ (Cuenca, 1926: 466-467)

Alberto Berenguer Carisomo caracteriza acertadamente este pasaje como una de las "rápidas instantáneas de "color local", que reflejan "el choque de la "nueva generación' romántica (...) con la anterior de cuño colonial" (Berenguer Carisomo, 1947: 319). Las palabras de don Diego pueden considerarse, además -sin olvidar que pertenecen a una obra de ficción-, como un índice del éxito de las obras extranjeras, no sólo francesas, si bien los autores de esta nacionalidad constituyen la gran mayoría en el repertorio que menciona el librero.

Más allá de su importancia, el circuito de las librerías no representa el único medio al que recurren los ávidos lectores. López atestigua, en su autobiografía ya citada, la práctica de la importación, llevada a cabo por individuos con recursos, de libros destinados al consumo privado. Tal es el caso de Santiago Viola, un afortunado y superficial heredero, aficionado a los bienes culturales: "Al sentir nuestro movimiento [el interés de López y sus amigos por las novedades literarias], [Viola] empleó unos veinte o veinticinco mil francos de su fortuna en mandar venir todos los libros de fama corriente en París, franceses, italianos, alemanes traducidos [...]" (López, s/a: 18). López y sus amigos -entre quienes se cuenta Alberdi- acudían "en tropel", atraídos por las novedades literarias que importaba Viola (López, s/a: 19). Dado que éste amaba ser el centro de atención, "nos prestaba sus libros, haciendo gala de generoso" (López, s/a: 19). Viola, por lo tanto, y al igual que Cané, compartía los libros adquiridos, contribuyendo de este modo a la difusión de la literatura y la cultura francesas en Buenos Aires.

La vía de acceso al conocimiento de la literatura francesa propiciada por la disponibilidad comercial de los libros -y la generosidad de sus dueños- se complementa y refuerza con la acción ejercida por determinadas personalidades prestigiosas en los círculos cultos de Buenos Aires. Esteban Echeverría, el vate romántico argentino por antonomasia, regresa en junio de 1830 a Buenos Aires, luego de pasar cinco años en Francia, en contacto directo con las novedades culturales europeas (Weinberg, 2006: 19-24). Alberdi recuerda el papel que desempeñó el poeta en la difusión de la nueva corriente literaria: "Por Echeverría, que se había educado en Francia durante la Restauración, tuve las primeras noticias de Lerminier, de Villemain, de Víctor Hugo, de Alejandro Dumas, de Lamartine, de Byron y de todo lo que entonces se llamó el romanticismo [...]" (Alberdi, 2010: 181).

El año de 1830 podría ser caracterizado, entonces, como un hito de alto valor simbólico. Mientras que las Trois Glorieuses sacuden el escenario político y cultural francés, el regreso de Echeverría a Buenos Aires impacta decisivamente en el panorama cultural argentino. La difusión de la nueva corriente literaria -a impulsos, como vimos, del caudaloso ingreso de obras europeas, particularmente francesas-

${ }^{3}$ Tanto la grafía como la puntuación de todas las citas pertenecientes a textos del siglo XIX fueron modernizadas. 
alcanza también a la actividad teatral. A partir de 1830 se verifican abundantes representaciones de piezas adscriptas al romanticismo francés. Vuelve a manifestarse así la preferencia por la dramaturgia gala que ya se había registrado con posterioridad a 1810, año de la constitución del primer gobierno patrio, sólo que en ese momento y en la década de 1820 -al decir de Raúl Castagnino- el repertorio estaba constituido fundamentalmente por piezas neoclásicas (Castagnino, 1989: 505). Según este crítico, los repertorios de los teatros porteños entre los años 1830 y 1852 se nutren exclusivamente de obras francesas y españolas, en su mayoría contemporáneas (Castagnino, 1989: 494). Castagnino señala aquí la "avidez de novedades" del público local y la necesidad de las empresas teatrales por satisfacer esa demanda (Castagnino, 1989: 505). Esta avidez por lo nuevo de los espectadores se corresponde con la búsqueda frenética y extasiada de las ideas y libros recién llegados de Europa, que pone de manifiesto López en su autobiografía.

\section{Ducange en las tablas de Buenos Aires}

Victor Ducange, Victor Hugo, Alexandre Dumas, Jean-François-Casimir Delavigne, Augustin-Eugène Scribe y René-Charles Guilbert de Pixérécourt son algunos de los románticos cuyas piezas suben a la escena porteña desde comienzos de la década de 1830 (Castagnino, 1989: 506-510). La recepción de la obra de Victor Henri Joseph Brahain Ducange -tal es su nombre completo- en la escena cultural de Buenos Aires constituye una problemática que todavía no ha sido abordada con la suficiente atención y profundidad. La librería de los hermanos Duportail registra en su catálogo de 1829 -y, por lo tanto, ofrece a la venta- cinco novelas de su autoría: Agathe, ou le petit vieillard de Calais (Paris, 1819); Albert, ou les amants missionnaires (Paris, 1820); Thélène, ou l'amour et la guerre (Paris, 1823); Les trois filles de la veuve (Paris, 1826) y L'artiste et le soldat, ou les fils de maître Jacques (Paris, 1827) (Parada, 2010: 64; 70; 76). Estos ejemplares, en su idioma original, seguramente estaban destinados a la comunidad de franceses residentes en Argentina, como sugiere Parada (2010: 18), aunque también a los lectores locales cultos que dominaban dicho idioma.

El personaje de don Diego en la pieza de Cuenca nombra a Ducange, como vimos, entre los autores más vendidos del momento. Si bien este librero ficticio no especifica el género al que pertenecerían las obras de Ducange $-\mathrm{y}$ las de los otros autores incluidos en su lista-, podemos suponer que se trata de novelas y, tal vez, de aquellas promocionadas en el catálogo de los Duportail. No obstante, podríamos imaginar que la referencia del librero contempla también las piezas teatrales de Ducange, si tenemos en cuenta la evocación ya citada de López: "Nos arrebatábamos [...] los dramas de Dumas y de Víctor Ducange [...]" (López, s/a: 17). Esta afirmación podría constituir una evidencia de la existencia de un circuito comercial para las obras teatrales, publicadas en formato de libro, y de la práctica del teatro leído. Encontramos una prueba adicional de esta forma de consumo del género en una carta publicada en el Diario de la Tarde comercial, político y literario. Los suscriptores de 
la epístola, que se identifican como "Unos concurrentes", comienzan su escrito afirmando que "Habíamos leído el Antonino [de A. Dumas], mas no vístolo en la escena" (Diario de la Tarde $\mathrm{N}^{\circ} 1083,16$ de enero de 1835, p. 2, col. 2). La práctica del teatro leído, sustentada en la circulación (a través de la compra-venta, préstamos, intercambios, etc.) de la versión impresa de las piezas, podríamos conjeturar, funcionaría de manera complementaria y subsidiaria al circuito de la representación.

La crítica literaria argentina del siglo XX -y, más concretamente, la teatral- no ha sido muy benigna con Ducange. Castagnino lo considera un "mediocre dramaturgo" que "supo escribir obras de eficacia directa en los auditorios poco exigentes" (Castagnino, 1989: 508), un "autor de segundo orden", uno de los dioses menores del romanticismo que sólo "imitan lo externo de la obras maestras" (Castagnino, 1989: 534). Este crítico reconoce, no obstante, que sus piezas -"truculentos melodramas"son del gusto popular, aunque este rasgo no constituiría, a su juicio, necesariamente una virtud: los autores como Ducange -afirma Castagnino- "a veces, por vulgares, están más cerca de lo popular" (Castagnino,1989: 534).

Berenguer Carisomo, por su parte, tras señalar el "elevadísimo porcentaje de teatro romántico francés" presente en las carteleras de Buenos Aires entre 1838 y 1852, recurre a una metáfora vitivinícola para distinguir entre el teatro "de buena cepa", como el de V. Hugo, y el "avinagrado", como el de Ducange y Scribe (Berenguer Carisomo, 1947: 280).

Ducange también era menospreciado, con argumentos y calificativos semejantes, por los intelectuales españoles de su época. Como afirma E. Allison Peers, Mariano José de Larra "no le tenía en buen concepto", aunque había traducido en 1832 empleando el pseudónimo de Ramón de Arriala- su drama Calas, con el nombre de Roberto Dillon (Peers, 1967: 283). En su crítica del drama Teresa, de A. Dumas ("Teresa. Drama en cinco actos, de Mr. Alejandro Dumas", publicada en El Español $\mathrm{N}^{\circ}$ 97, del 5 de febrero de 1836.), Larra compara a Ducange con Victor Hugo, y afirma que aquel "es un dramaturgo de boulevard [...]; no es un escritor de primer orden, ni por la esencia de sus obras, ni por su estilo" (Larra, 1989: 812).

Por otra parte, y en el mismo artículo dedicado a Teresa, Larra destaca esa cercanía de Ducange con respecto a lo popular que posteriormente resaltaría Castagnino, al llamarlo "el abastecedor de las producciones dramáticas del populacho" (Larra, 1989: 812). Este mismo rasgo es señalado en la nota necrológica de Ducange aparecida sin firma en El Vapor ("Crónica teatral", El Vapor. Periódico mercantil, político y literario de Cataluña, año I, $\mathrm{N}^{\circ} 103,15$ de noviembre de 1833, p. 3, cols. 1-3. $)^{4}$ : "Era el poeta dramático de la plebe, el único que penetraba el secreto de sus instintos, odios y supersticiones" (p. 3, col. 1). El autor de la nota también lo llama "poeta de los arrabales" (p. 3, col. 3), aunque ambas denominaciones no confluyen en una caracterización negativa del dramaturgo.

\footnotetext{
${ }^{4}$ Para Peers, esta necrológica "da buena idea de la popularidad de Ducange y de la naturaleza de su aceptación en España” (Peers, 1967: 283).
} 
En el Río de la Plata, Ducange ostenta un singular galardón. El 20 de setiembre de 1830 se representa la versión adaptada por Fernández Madrid de la novela de Chateaubriand, Atala o Los amores del desierto. Castagnino identifica a esta pieza como la primera de carácter romántico que se verifica en Buenos Aires (Castagnino, 1989: 532). No obstante, señala que "la versión dramática está realizada en el molde de la tragedia académica, con sus cinco actos, sus unidades de rigor" (Castagnino, 1989: 532-533). Debido a esta circunstancia, el drama de Ducange 30 años o La vida de un jugador (Trente Ans, ou la Vie d'un Joueur, 1827), estrenado el 28 de julio de 1831, constituye, para Castagnino, "la primera obra, de autor enrolado expresamente en la tendencia [romántica] y concebida en ella, que sube a la escena porteña" (Castagnino, 1989: 533). Esta situación privilegiada de Ducange provoca el desconcierto del crítico, a quien le "llama la atención que esta introducción de lo romántico en el teatro de Buenos Aires no se realice a través de la producción de figuras estelares; sino por la de dii minores" (Castagnino, 1989: 534).

\section{Un jugador afortunado}

Los avisos publicados en la prensa para anunciar y promocionar las obras ofrecen material interesante para abordar el estudio de la recepción de las piezas teatrales. Debemos tener en cuenta, no obstante, la limitación inherente a este tipo de documentos. Liliana López, al referirse a los "comentarios acerca de las funciones" aparecidos en el Diario de la Tarde en 1838, les resta importancia:

En todos los casos, los textos no pueden considerarse exponentes de la crítica sino principalmente anuncios que acompañaban la información con adjetivos repetitivos y vacíos de significado: "preciosísima comedia", "divertido fin de fiesta", "asunto interesante", "graciosa comedia" o "acreditado drama” (López, 2005: 559-560).

Si bien coincidimos en líneas generales con esta afirmación, consideramos que no debe dejarse de lado un análisis crítico de los anuncios, contemplando naturalmente el género al que pertenecen y la finalidad publicitaria que persiguen. Más allá de la adjetivación estereotipada e interesada, estos brindan en ocasiones información útil para medir el grado de consagración de un autor y el proceso de su recepción. Del mismo modo, la información omitida en estos anuncios puede resultar relevante.

Un día antes del estreno de Treinta años o La vida de un jugador, el 27 de julio de 1831, aparece en el Diario de la Tarde, un aviso sobre la representación de dicho drama (Diario de la Tarde, Comercial, político y literario ${ }^{5} \mathrm{~N}^{\circ} 58$, miércoles 27 de julio de 1831, p. 2, col. 2, sección “Avisos"). Se anuncia que se tratará de una función extraordinaria en beneficio de Juana Cañete, bailarina del Coliseo Provisional, lugar de la representación. Treinta años es caracterizado como un "interesante drama de espectáculo" (p. 2, col. 2). El aviso concluye con el anuncio del "gran baile nuevo"

\footnotetext{
${ }^{5}$ En adelante, DT. Este aviso se repite en DT $\mathrm{N}^{\circ} 59$ del jueves 28 de julio de 1831, p. 2, col. 2.
} 
con el que cerraría el espectáculo, El marido sorprendido en un baile de máscaras, y con el dato de que los "señores abonados" tendrán preferencia "hasta las 12 del día de la función" (p. 2, col. 2). Resulta significativa la ausencia de cualquier mención del autor de la pieza.

Según consigna Castagnino, Treinta años gozó de gran popularidad, al punto de figurar en la lista de las más representadas en Buenos Aires en el período comprendido entre los años 1830 y 1852, junto a El Trovador, de Antonio García Gutiérrez, Otelo, de Shakespeare, y El abate Lépée (L'Abbé L'Epée) de Jean-Nicolas Bouilly (Castagnino, 1989: 506; 508; 533).

Podemos constatar, sin pretensiones de exhaustividad, la aparición de avisos semejantes al citado a lo largo de los meses y años posteriores a su estreno. El jueves 4 de agosto de 1831 se anuncia en el Diario de la Tarde (DT N ${ }^{\circ} 65$, jueves 4 de agosto de 1831, p. 2, col. 2, sección "Avisos") ${ }^{6}$ la representación del drama de Ducange para el día siguiente, que en esta ocasión sería acompañado por un sainete, titulado Lo que puede el hambre (p. 2, col. 2). Esta vez el título de la pieza presenta una leve diferencia con respecto al anuncio anterior: Treinta años o La vida del jugador, en lugar de de un jugador, tal vez debido a un error de imprenta. El nombre del autor continúa sin aparecer. La misma variación con respecto al título y la misma ausencia del nombre de Ducange se registra en el anuncio de la función del 19 de agosto del mismo año, en la cual se representaría también la pieza en un acto titulada La florentina (DT N ${ }^{\circ} 77$, viernes 19 de agosto de 1831, p. 2, col. 2, sección “Avisos"). Pareciera que el título queda fijado de ese modo -La vida del jugador-, ya que así vuelve a registrarse en un aviso, esta vez de La Gaceta Mercantil, de la función prevista para el 5 de octubre de 1831. La indicación del espectáculo complementario nunca falta -esta vez sería el sainete Las cuatro bodas-, pero sí el nombre del autor del drama principal (La Gaceta Mercantil. Diario comercial, político y literario ${ }^{7} \mathrm{~N}^{\circ}$ 2301, miércoles 5 de octubre de 1831, p. 3, col. 2, sección "Avisos nuevos").

Tras la reposición de la pieza el día 5 de agosto, se publica en el Diario de la Tarde una breve nota (DT $\mathrm{N}^{\circ}$ 68, lunes 8 de agosto de 1831, p. 1, cols. 1-2) que merece nuestra atención por varios motivos. Para Castagnino, constituye una prueba de que la novedad romántica -inaugurada en teatro, según él, con la representación de Treinta años- "no pasa inadvertida" y un índice de "la reacción de cierto sector del público" (Castagnino, 1989: 533). El texto, sin firma, podría atribuirse tal vez a alguno de los editores del periódico, ya que no se incluye en la sección destinada a la correspondencia de los lectores.

El objetivo de la nota es abogar por la repetición del drama de Ducange: "En estos últimos días" - comienza el autor del artículo- "se ha exhibido en nuestro teatro una pieza, cuya repetición no puede menos de interesar a la moral del país" (p. 1, col. 1).

\footnotetext{
${ }^{6}$ Este aviso se repite en DT No 66 del viernes 5 de agosto de 1831, p. 2, col. 2.

${ }^{7}$ En adelante, LGM.
} 
El título de la pieza no se menciona sino hacia el final: "Sería conveniente que el Sr. asentista ${ }^{8}$ hiciese representar con alguna frecuencia La vida del jugador" (p. 1, col. 2). La versión del título con la contracción del parecería haberse impuesto sobre aquella que lleva el pronombre indefinido. El nombre de Ducange, al igual que ocurría en los avisos analizados, no es mencionado.

El pedido de repetición del drama se sustenta en el valor moral y en la función de profilaxis social que se le atribuye y en ese sentido se orientan los elogios:

[...] aquella composición es interesante, y sobremanera útil en los países donde la pasión al juego arruina frecuentemente las mejores fortunas, sumiendo en la mendicidad, y en todo género de vicios, a los que poco antes gustaban las comodidades de una vida honesta y laboriosa (p. 1, cols. 1-2). ${ }^{9}$

Debido a esta virtud de la pieza, que la torna recomendable, el autor de la nota puede tolerar sus defectos e "impropiedades", que, no obstante, no se priva de señalar: "se ve correr el largo período de 30 años, en el breve espacio de dos horas, con otras circunstancias, que contrarían las primeras reglas del arte" (p. 1, col. 1). Las "primeras reglas del arte" remiten a aquellas sancionadas por los antiguos (Aristóteles, Horacio) y recuperadas por los clasicistas de los siglos XVII y XVIII (Boileau). La crítica apunta directamente a la violación de la regla aristotélica de la unidad de tiempo.

En un artículo aparecido en Santiago de Chile una década después, firmado por Salvador Sanfuentes ("Romanticismo", en El Semanario de Santiago, № 2, Santiago de Chile, 21 de julio de 1842, pp. 12-13, cols. 1-2 $)^{10}$, se repite la crítica a la pieza, así como la actitud tolerante hacia la misma, en función de su valor moral:

Jamás hemos criticado a Victor Ducange por habernos hecho recorrer en su Jugador el intervalo de 30 años en una sola noche; (...). Sí, tan latos como todo esto son nuestros principios, pero exigiremos siempre que el autor no se tome estas libertades sin necesidad, antes bien se valga de ellas solo para admirarnos con nuevas bellezas, o darnos lecciones terribles como las del Jugador (Pas, 2013: 182).

A diferencia de Sanfuentes -quien deja en claro en el artículo citado que no pretende alistarse "ciegamente en las banderas del clasicismo riguroso" (Pas, 2013: 182) $-^{11}$, la postura del autor de la nota de 1831 está en sintonía con los preceptos neoclásicos. Así lo señala Castagnino, al referirse al autor como "un seudoclásico que no ha de tardar en convertirse al nuevo credo", caracterizado por los siguientes rasgos: "resabio retórico, prurito de las reglas y recetas aprendidas" (Castagnino, 1989: 533). La conversión a la que hace referencia el crítico alude a la facultad que le atribuye al "articulista"-como él lo llama-de captar y valorar la novedad literaria que representa

\footnotetext{
${ }^{8}$ El asentista "era una mezcla de empresario y administrador del teatro" (Peña, 2008: 385).

${ }^{9}$ Las cursivas pertenecen al original.

${ }^{10}$ Accedimos al artículo a través de la compilación realizada por Hernán Pas (2013).

${ }^{11}$ Las cursivas pertenecen al original.
} 
la pieza: "pero hay, también [en el autor de la nota], algo así como el respirar un aire distinto, el entrever un rayo luminoso en las tinieblas" (Castagnino, 1989: 533).

Años más tarde, al estrenarse otra obra de Ducange, escrita en colaboración con M. Anicet Bourgeois, la prensa periódica vuelve a referirse - esta vez de una manera hiperbólica- a la eficacia moral de Treinta años. Pocos días después de la representación de La Educanda en Londres o El Colegio de Tonnigton (Le Couvent de Tonnington ou La Pensionnaire, 1830), que tiene lugar el 19 de agosto de 1834, se desata una polémica en la sección "Correspondencia" del Diario de la Tarde y La Gaceta Mercantil ${ }^{12}$. Uno de los lectores que interviene en el debate -en un artículo titulado "Algunas observaciones, de las muchas a que da lugar un artículo inserto en el Diario de la Tarde del martes, y firmado por dos Anti-Románticos" (LGM N ${ }^{\circ}$ 3373 , viernes 29 de agosto de 1834, p. 2, cols. 2-4)- enrolado bajo la bandera del romanticismo, defiende la pieza de los ataques de los clasicistas, y argumenta sobre la necesidad de la violación de las unidades de tiempo y acción para que una obra pueda lograr su efecto:

[...] ajustándose a los preceptos de la escuela clásica, mal puede un autor presentar el cuadro de los descarríos de un vicioso igual al Jugador de Ducange, o de la especie de los que figuran en la Educanda, sin incurrir en uno de estos defectos o considerar el vicio por una sola de sus faces o incluir en cansados monólogos y diálogos interminables, las otras circunstancias de la vida del protagonista, poniendo en acción solo una de ellas (p. 2, col. 2).

Los románticos, según afirma el autor de la epístola, al presentar "una larga cadena de sucesos" y no sólo "un accidente de la vida", logran conmover de manera más eficaz a la audiencia (p. 2, col. 2). En este sentido, Treinta años se destaca por sus efectos cuasi milagrosos, acerca de los cuales el autor brinda un testimonio personal:

A esto, independientemente del talento de Ducange, debe atribuirse el prodigioso efecto de sus composiciones. Sin citar ninguno de los numerosos casos que se leen en su biografía de conversiones a la virtud y de empresas de juego que le han ofertado ingentes sumas porque no diera a luz sus piezas, puedo presentar el testimonio de personas que por muchos años tuvieron la vergonzosa manía del juego, y quienes se curaron radicalmente de esta peligrosa enfermedad aterradas por el espectáculo del Jugador de Ducange (p. 2, col. 3).

Esta carta, podemos suponer, habría despertado nuevamente el interés en el drama. Tal vez, el director de la compañía teatral juzgó que se trataba de una oportunidad que no se podía desaprovechar. Lo cierto es que el 30 de octubre de 1834 Treinta años vuelve a subir a escena, función que se repite el $1^{\circ}$ de noviembre (Castagnino, 1989: 638). El 12 de diciembre de ese mismo año se publica en el Diario de la Tarde un nuevo pedido de repetición de la pieza. A diferencia del anterior, esta vez aparece incluido en la sección "Correspondencia" y firmado, de un modo génerico, por "Un aficionado a lo útil" (DT No 1056, viernes 12 de diciembre de 1834, p. 2, cols. 1-2).

${ }^{12}$ Para Castagnino, se trata de "la primera polémica que sobre la nueva ideología [el romanticismo] registra el periodismo local” (Castagnino, 1989: 534). 
El autor de la misiva, quien interpela al director de la compañía, empieza su intervención de manera cautelosa y cortés. Tras manifestar que comprende plenamente que no es de su incumbencia la selección del repertorio teatral, plantea su solicitud:

Sin que Ud. crea que pretendo abrogarme el derecho de elegir las piezas dramáticas que deben darle al público, pues que nadie está más convencido que yo que esto compete exclusivamente a Ud., y aun diré más, que este encargo lo desempeña Ud. a satisfacción general, me permitirá le ruegue se sirva darnos lo más pronto posible, y si fuere dable una vez de cuando en cuando Los 30 años o la Vida de un Jugador (p. 2, col. 1).

La fórmula "una vez de cuando en cuando" remite a la expresión "con alguna frecuencia" empleada en el artículo de 1831. En la carta, a diferencia de aquel texto, se percibe cierto tono apremiante: "se sirva darnos lo más pronto posible" (p. 2, col. $1)^{13}$. Este tono se justificaría por el valor profiláctico que se atribuye a la pieza -rasgo presente también en la nota de 1831 - y por la vigencia y extensión del mal que ésta vendría a curar:

No es preciso profesar el rigorismo de los principios clásicos para conocer los defectos de que este drama adolece; pero también es cierto que no se necesita ser un apologista del romantismo para ver en ella una fuerte lección contra un vicio por desgracia harto común en nuestra sociedad, y para por lo mismo creer que su exhibición hecha con maestría, sirve siempre como un freno a la juventud dispuesta a lanzarse en los funestos peligros de una pasión que tiene como ninguna otra la doble desventaja de alimentarse con los reveses como con los triunfos (p. 2, cols. 1-2).

El aficionado, al igual que el autor del artículo de tres años atrás, reconoce que el drama tiene defectos, con la diferencia de que no se detiene en enumerarlos ni brinda ninguna especificación al respecto. Su posicionamiento ideológico es cauteloso, como si pretendiera evitar involucrarse en problemas o discusiones estéticas: ni del lado del "rigorismo" del clasicismo, ni "apologista del romantismo". Al "aficionado a lo útil", como su nombre lo indica, sólo le importa la utilidad, el provecho moral y social que puede sacarse de la pieza. Por ello, puede adoptar una postura equidistante con respecto a una y otra escuela.

El director de la compañía parece haber tomado nota del pedido. Treinta años vuelve a representarse el 30 de diciembre de 1834 (Castagnino, 1989: 639). La siguiente representación tendrá lugar seis meses después, el 25 de junio de 1835 (Castagnino, 1989: 642). Las solicitudes de 1831 y 1834 constituirían una muestra de la aceptación de la pieza por parte del público de la época. Al mismo tiempo, podríamos conjeturar, habrían contribuido a instalar la obra en el gusto de los potenciales espectadores. En este sentido, podríamos pensar también en una estrategia rudimentaria para atraer público. Los pedidos, en ese caso, no serían tan ingenuos.

${ }^{13}$ La cursiva nos pertenece. 
Cinco años más tarde, en 1839, y del otro lado del Río de la Plata, en la vecina ciudad de Montevideo, se estrena Los 30 años o La vida de un Jugador. Si confrontamos la información brindada en uno de los anuncios de la representación ("Teatro dramático", Revista Oficial N 90, Vol. 1, Montevideo, viernes 15 de marzo de 1839, p. 3, col. 2, sección "Avisos") con los de Buenos Aires ya analizados, llaman la atención algunos detalles. Dejando de lado las variaciones, poco significativas, en el título, la presencia del nombre del autor y la caracterización de la pieza constituyen diferencias relevantes: "Se está preparando para poner en escena el Martes próximo 19 del corriente a beneficio de la Sra. Guillermina Prigioni y del Sr. Felipe Martínez, el célebre drama de espectáculo de Victor Ducange [...]" (p. 3, col. 2) ) $^{14}$, anticipa la Revista Oficial, y promete que "será exornado con todo el aparato teatral que requiere su argumento" (p. 3, col. 2). La pieza, tras las múltiples representaciones en Buenos Aires, se ha ganado el epíteto de "célebre", al mismo tiempo que su autor se ha hecho acreedor al privilegio de ser mencionado.

\section{Célebre, inmortal e ingenioso}

Según sostiene Castagnino, "la segunda obra netamente romántica que se exhibe en Buenos Aires" también pertenece a Ducange. Se trataría de Quince años o Los efectos de la perversión (Castagnino, 1989: 533). Unos días antes de su estreno, previsto para el 21 de febrero de 1832, se publica un anuncio en La Gaceta Mercantil (LGM N ${ }^{\circ}$ 2410, viernes 17 de febrero de 1832, p. 3, col. 2, sección "Avisos nuevos"), donde se informa que se trata de una función extraordinaria a beneficio del actor Santiago González. En el aviso se califica a la pieza de "interesante drama-histórico" y se aclara que es "nuevo en nuestra escena y de mucho interés" (p. 3, col. 2). Al igual que en los avisos de Treinta años analizados, el nombre de Ducange no se menciona. No obstante, la fórmula empleada para referirse a él resulta por demás significativa: "el mismo autor de La Vida de un Jugador" (p. 3, col. 2). El título de la pieza se ha visto reducido a una de sus partes, tal vez por cuestiones de espacio. La importancia de destacar el elemento considerado distintivo y que remite al valor otorgado a la pieza -su efecto sobre el vicio del juego- sería, a nuestro entender, el motivo de que se haya conservado el subtítulo en lugar del título propiamente dicho. El drama se ha convertido en una suerte de marca reconocible, más aún que su autor.

Debemos señalar, no obstante, que Ducange no es el autor de Quince años o Los efectos de la perversión. Este drama, en realidad, tal como lo establece Gabriel Sansano, es la versión española de Le Paysan perverti, où Quinze ans de Paris, de Emmanuel Théaulon, realizada por Francesc Renart i Arús, cuyo título original habría sido El labrador pervertido o Quince años en París (Sansano, 2010: 178). La versión de Renart ${ }^{15}$ se publica en 1829 , año en que también se representa en Barcelona,

\footnotetext{
${ }^{14}$ La cursiva es nuestra.

${ }^{15}$ El título, en realidad, es Quince años o Efectos de la perversión.
} 
promocionándose de una manera peculiar: en los carteles publicitarios aparece asociada a Treinta años. De allí que Los efectos de la perversión se haya atribuido erróneamente a Ducange (Sansano, 2010: 177). A nuestro entender, contribuyó a la confusión el hecho de que este dramaturgo cuenta entre su producción con una pieza, Il y a seize ans (1831), cuya versión española se conoce como Quince años ha ó Los incendiarios de Pre-in-saint-Paul, representado en Buenos Aires recién el 25 de abril de 1837 (Castagnino, 1989: 649). Podemos suponer que el anuncio de 1832 publicado en La Gaceta Mercantil habría copiado la información proporcionada por el texto publicitario español. Podría sospecharse, en la asociación con Treinta años, una confusión interesada, con el objeto de aprovecharse del renombre de dicha pieza. Sea como fuere, constituye una instancia más que interesante de las peripecias de La vida de un Jugador de uno y otro lado del Atlántico.

En agosto de 1834 sube a escena La Educanda en Londres o El Colegio de Tonnigton, obra escrita, como dijimos antes, en colaboración por Ducange y Bourgeois. Sin embargo, en los avisos que anuncian su estreno en el Diario de la Tarde (DT N $\mathrm{N}^{\circ}$ 961, lunes 18 de agosto de 1834, p. 3, col. 4, sección "Avisos nuevos" ${ }^{16}$ el director de la compañía teatral del Coliseo Provisional, Antonio González, atribuye la pieza sólo al primero: "El Martes 19 de Agosto de 1834 a beneficio del director que firma se representará el interesante drama, en 6 actos y de grande espectáculo, original del ingenioso Victor Ducange [...]" (p. 3, col. 3) ${ }^{17}$. Con ocasión de la segunda representación de la pieza (a la semana siguiente de su estreno), la actriz Manuela Funes de Casacuberta - a cargo del papel protágonico y beneficiaria de dicha función- suscribe un anuncio en el Diario de la Tarde (DT N ${ }^{\circ} 967$, lunes 25 de agosto de 1834, p. 3, col. 2, sección "Avisos Nuevos") donde se refiere a La Educanda en Londres como "el interesante drama del célebre Victor Ducange" (p. 3, col. 2). La consagración del dramaturgo es ya un hecho: al epíteto de "célebre" -que se repite en el segundo anuncio citado-, se suma ahora el de "ingenioso". Por otra parte, ya no se considera necesario mencionar que es el autor de La vida de un jugador para hacerlo reconocible.

La fama de la que goza Ducange en ese momento puede verificarse también en la polémica en torno a La Educanda en Londres, a la que hicimos referencia más arriba. "Dos Románticos", tal como se autodenominan, en la carta que desata el debate (LGM No 3367, viernes 22 de agosto de 1834, p. 2, col. 4) colman de elogios a la pieza que acaba de estrenarse: "El solo nombre de su autor bastó para prevenir nuestros ánimos a algo de grandioso y sublime; nuestras esperanzas no fueron frustradas: La Educanda en Londres ha llenado nuestros deseos" (p. 2, col. 4). El

${ }^{16}$ Este aviso se repite en el DT $N^{\circ} 962$ del día siguiente, p. 3, col. 3.

${ }^{17} \mathrm{Si}$ bien el drama original se compone de tres actos, la versión que se representa en Buenos Aires consta de seis, tal como se informa en el aviso citado. 
nombre de Ducange ya no resulta extraño, al menos para quienes se declaran partidarios de la estética romántica.

La gravitación de Treinta años sigue siendo significativa, o al menos así se la percibe, a los efectos de promoción de las piezas representadas. Un aviso aparecido en La Gaceta Mercantil (LGM N ${ }^{\circ}$ 3432, lunes 10 de noviembre de 1834, p. 3, col. 2, sección "Avisos nuevos") ${ }^{18}$ informa sobre el estreno de Roberto Dillon o El católico de Irlanda (Calas, 1819), previsto para el 13 de noviembre de 1834, en estos términos: "Después de la Sinfonía de costumbre la Compañía Dramática ejecutará un interesante drama de gran espectáculo del célebre autor de La Vida de un Jugador, Victor Ducange, en 3 actos [...]" (p. 3, col. 2). Nuevamente, aparece la mención de la obra responsable de la consagración de Ducange, con la diferencia significativa de que en este caso sí se registra el nombre del autor, acompañado esta vez del calificativo de "célebre". La fórmula para referirse a Ducange -que ha ganado en complejidad con respecto a la empleada en el aviso de Quince años- establece explícitamente la relación entre la celebridad alcanzada y Treinta años. Más allá de esta referencia al ya canonizado drama, el aviso recurre a otras estratagemas para ponderar los méritos de Roberto Dillon, capaz de ganarse por sí mismo la aprobación del público. La apelación a un "público conocedor", capaz de evaluar con justicia una obra teatral, es una de esas estratagemas: "No me toca hacer ningún análisis de esta composición, pues el público conocedor, a quien la dedico, juzgará de su verdadero mérito" (p. 3, col. 2). Por otra parte, el autor del anuncio desliza el dato del éxito de la representación de la obra en Madrid, con la pretensión, seguramente, de replicarlo en Buenos Aires: "y sí solo diré que en Madrid ha sido representada a fines del año 33, y que ha merecido una aceptación general en el Teatro del Príncipe, donde se ejecutó por primera vez" (p. 3, col. 2) ${ }^{19}$.

La expresión empleada para caracterizar a Roberto Dillon en el texto analizado se repite de manera casi idéntica en el aviso del estreno de Pólder o El verdugo de Ámsterdam (Polder, ou le Borreau d'Amsterdam, 1828), programado para el 27 de noviembre de 1834 (LGM N 3442, sábado 22 de noviembre de 1834, p. 3, col. 3, sección "Avisos nuevos"): "Se está preparando para la semana entrante, a beneficio de la Sra. Ana Campomanes, el drama de gran espectáculo del célebre Victor Ducange, y en 6 actos [...]" (p. 3, col. 3) ${ }^{20}$. Sólo faltan el adjetivo "interesante" que calificaba a Roberto Dillon y, dato no menor, la alusión a La Vida de un Jugador. Por otra parte, como ocurría en los anuncios de La Educanda en Londres, se omite el nombre del co-autor de Pólder, en este caso, René-Charles Guilbert de Pixérécourt.

Ramón de Mesonero Romanos da cuenta del empleo generalizado del calificativo de "célebre" para referirse al dramaturgo. En el episodio titulado "Entierro de Victor

\footnotetext{
${ }^{18}$ El aviso se repite en LGM No 3433 del miércoles 12 de noviembre (p. 3, col. 3) y $\mathrm{N}^{\circ} 3434$ del jueves 13 de noviembre (p. 3, col. 2).

${ }^{19}$ Las cursivas pertenecen al original.

${ }^{20}$ Las cursivas pertenecen al original.
} 
Ducange", incluido en sus Recuerdos de viaje por Francia y Bélgica en 1840-1841, el escritor español relata que, habiendo asistido al funeral del dramaturgo en París, entabla conversación con un periodista que integraba el cortejo fúnebre. Cuando Mesonero se presenta como un español que conoce la obra de Ducange, el periodista se sorprende de que el autor de Treinta años sea reconocido en España. Mesonero le expone entonces los motivos de dicha fama, entre los que menciona el hecho de que "se recalca sobre el epíteto del célebre Victor Ducange" (Mesonero Romanos, 1862: $162)^{21}$.

La expresión admite, en ocasiones, variantes interesantes. El calificativo de "célebre" puede ser reemplazado por un sinónimo, incluso más enaltecedor. Con motivo de la reposición de Roberto Dillon el 6 de junio de 1838, La Gaceta Mercantil (LGM N 4490, martes 5 de junio de 1838, p. 4, col. 2, sección "Avisos nuevos") anuncia que "La Empresa tiene la satisfacción de poner en escena uno de los más acreditados dramas de grande espectáculo que goza de la mayor celebridad, tanto por su interesante argumento, como por pertenecer al inmortal Ducange" (p. 4, col. 2$)^{22}$. Roberto Dillon ya ha adquirido el renombre suficiente como para ser caracterizado con estas palabras superlativas. Cuatro años después de su estreno, ya no necesita de la mención de Treinta años, del mismo modo que, aparentemente, tampoco la necesitaban La Educanda en Londres y Pólder. Con la finalidad de persuadir a los potenciales espectadores, el aviso menciona méritos propios de Roberto Dillon -"su interesante argumento"- y la gloria alcanzada por su autor.

\section{Consideraciones finales}

El análisis de los avisos publicados en la sección de teatro de la prensa constituye una operación valiosa que no debe soslayarse. En los anuncios publicados por La Gaceta Mercantil y el Diario de la Tarde, en el contenido que ofrecen y en la forma de presentar dicho contenido, se revelan las estrategias promocionales de los empresarios y directores teatrales, y su adaptación al gusto de los espectadores, gusto que, al mismo tiempo y en un complejo proceso de retroalimentación, contribuyen a determinar. Por otra parte, son también de gran utilidad las cartas de lectores y textos editoriales, que permiten rastrear $-\mathrm{O}$ al menos intentarlo- al escurridizo lector y espectador "real", que constituye, para Yves Chevrel, el sujeto de los estudios comparatistas de recepción (Chevrel, 1994: 170). Los pedidos de reiteración de una pieza teatral -como el caso de Treinta años-o incluso las polémicas periodísticas como la que genera el estreno de La Educanda en Londres- constituyen índices de la aceptación o rechazo de dichas piezas por parte de la audiencia, o de un sector de ella, al menos.

\footnotetext{
${ }^{21}$ La cursiva pertenece al original.

${ }^{22}$ El aviso se repite en LGM N ${ }^{\circ} 4492$, del miércoles 6 de junio (p. 3, col. 2, sección “Avisos nuevos”). Las cursivas pertenecen al original.
} 
Tanto los anuncios como las cartas de la sección "Correspondencia" y los textos editoriales nos ofrecen la oportunidad de analizar la recepción de las obras teatrales de Ducange en Buenos Aires y de reconstruir la trayectoria de su consagración como dramaturgo entre el público local de la década de 1830. La trayectoria se inicia, como ya vimos, con el estreno de Treinta años o La vida de un Jugador en 1831. Esta pieza instala su nombre en la audiencia, y en las páginas de los periódicos, y le permite hacerse acreedor de los epítetos de "célebre", "inmortal" e "ingenioso", al mismo tiempo que funciona como carta de presentación autorizada de otras piezas del mismo autor (y de una atribuida erróneamente a él). Este relato de la consagración de Ducange, no obstante, debe interpretarse con cautela. Los papeles que desempeñan en este relato el director, el empresario teatral y los espectadores -aquellos que se animan a escribir una carta al periódico- suelen confundirse o entremezclarse, y resulta difícil distinguirlos con claridad entre las sombras, una vez que cae el telón.

\section{REFERENCIAS BIBLIOGRÁFICAS}

Alberdi, J. B., (2010) "Mi vida privada que se pasa toda en la República Argentina", in Alberdi, J. B., Palabras de un ausente y otros escritos íntimos. Buenos Aires, Emecé, pp. 159-193.

Baquero Escudero, A. L., (2002) "Novela epistolar y traducción: Marchena y La nouvelle Héloïse", in Lafarga, F., Palacios, C. \& A. Saura, (eds.), Neoclásicos y románticos ante la traducción. Murcia, Universidad de Murcia, pp. 391-404.

Berenguer Carisomo, A., (1947) Las ideas estéticas en el teatro argentino. Buenos Aires, Comisión Nacional de Cultura - Instituto Nacional de Teatro.

Binayán, N., (1926) "Noticia", in Cuenca, C., Don Tadeo. Buenos Aires, Instituto de Literatura Argentina, pp. 365-366.

Castagnino, R. H., (1989) El teatro en Buenos Aires durante la época de Rosas. Tomo II. Buenos Aires, Academia Argentina de Letras.

Chevrel, Y., (1994) "Los estudios de recepción”, in Brunel, P. \& Y. Chevrel (dirs.), Compendio de literatura comparada. México, Siglo Veintiuno, pp. 148-187.

Cuenca, C., (1926) Don Tadeo. Buenos Aires, Instituto de Literatura Argentina.

Larra, M. J. de, (1989) Artículos. Barcelona, Ediciones B.

López, L., (2005) “La crítica (1700-1884)”, in Pellettieri, O. (dir.), Historia del teatro argentino en Buenos Aires. Vol. 1: El período de constitución (1700-1884). Buenos Aires, Galerna, pp. 551-569.

López, V. F., (s/a) "Autobiografía", in Evocaciones históricas. Buenos Aires, Jackson.

Martino, L. M., (2016) "La auto-representación de un sujeto romántico: Mi vida privada de Juan Bautista Alberdi", in Mitologías Hoy. Revista de pensamiento, crítica y estudios literarios latinoamericanos. $\mathrm{N}^{\circ} 14$, pp. 147-161.

Mesonero Romanos, R. de, (1862) Recuerdos de viaje por Francia y Bélgica en 18401841. Madrid, Estab. Tipog. de D. Francisco de Paula Mellado. 
Parada, A. E., (2002) "El orden y la memoria en una librería porteña de 1829: el catálogo de la librería Duportail Hermanos", in Información, cultura y sociedad. $\mathrm{N}^{\circ} 7$, pp. 9-80.

Pas, H. (ed.), (2013) El romanticismo en la prensa periódica rioplatense y chilena. Ensayos, críticas, polémicas (1828-1864). La Plata, Universidad Nacional de La Plata.

Peers, E. A., (1967) Historia del movimiento romántico español. Tomo I. Madrid, Gredos.

Peña, M., (2008) "Consideraciones preliminares sobre un drama heroico novohispano del siglo XVIII: La lealtad americana, de Fernando Gavila", in Arellano, I. \& J. A. Rodríguez Garrido (eds.), El teatro en la Hispanoamérica colonial. Madrid - Frankfurt am Main, Universidad de Navarra, Iberoamericana, Vervuert, pp. 383-394.

Sansano, G., (2010) "Francesc Renart i Arús (1783-1853) i els orígens del teatre català vuitcentista", in Catalan Review: international journal of Catalan culture. $\mathrm{N}^{\circ} 24$, pp. 171-188.

Vázquez, A. E., (2015) "Novelas francesas en el Río de la Plata: los anuncios de compra y venta de libros en la prensa entre 1830 y 1835", in Aiello, F. (ed.), Estudios argentinos de literatura francesa y francófona: filiaciones y rupturas. Mar del Plata, Universidad Nacional de Mar del Plata, pp. 439-446.

Weinberg, F., (1977) El salón literario de 1837. Con escritos de M. Sastre - J. B. Alberdi - J. M. Gutiérrez - E. Echeverría. Buenos Aires, Hachette.

Weinberg, F., (2006) Esteban Echeverría. Ideólogo de la segunda revolución. Buenos Aires, Taurus. 